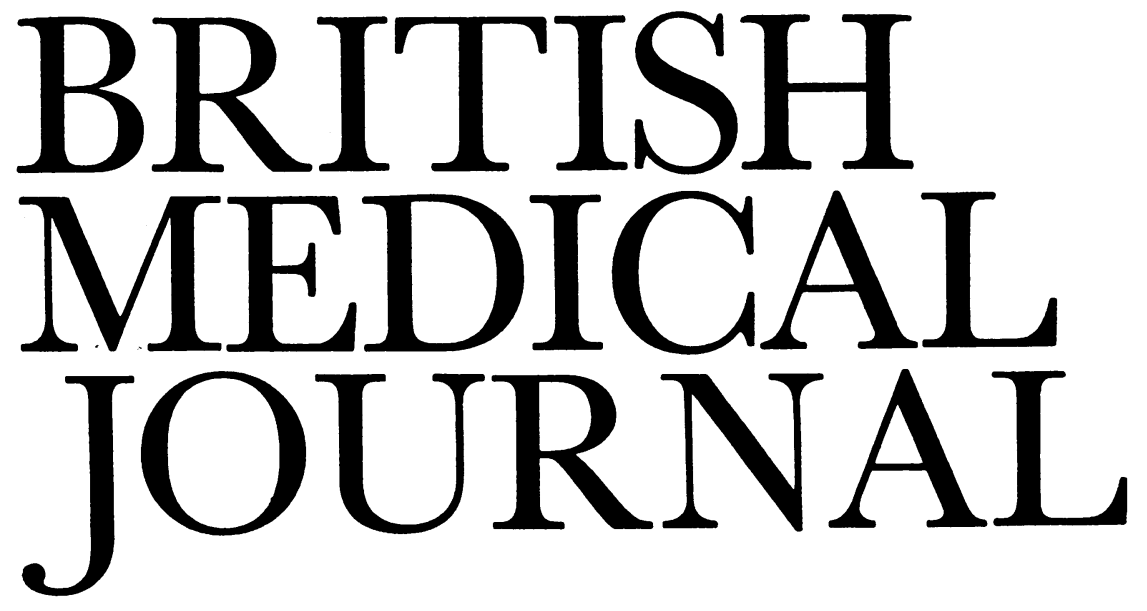

LONDON SATURDAY 6 FEBRUARY 1971

\title{
Facilities for Treating Terminal Renal Failure
}

In $1966 \mathrm{H}$. E. de Wardener ${ }^{1}$ calculated that every year about 2,200 people aged between 16 and 55 years in England and Wales died from renal failure. All but a few of these would probably have been suitable for regular dialysis treatment. Since then similar death rates have been reported from other countries, ${ }^{2}{ }^{3}$ and in a recent issue of the B.M.F. R. A. Branch and his colleagues have reported the results of a careful survey of the incidence of renal failure among a population of 120,000 in South Wales. ${ }^{4}$ In three years they found 14 patients aged between 15 and 60 years who might have been suitable for regular dialysis treatment, and they calculated that a similar incidence throughout the country would produce 2,000 new cases of irreversible renal failure each year. To this total should be added about 100 children $^{5}$ and rather more adults who are older than these arbitrary age limits but who are still leading useful and enjoyable lives.

At the end of June 1970 a survey of 34 dialysis units in England and Wales (population 49 million) showed that these were treating a total of 894 patients and were planning to extend this to between 2,500 and $3,000 .{ }^{6}$ Once a patient is established on regular haemodialysis treatment his prognosis is surprisingly good, ${ }^{7}$ and probably the ten-year survival rates will be about $60 \%$. Thus if all suitable patients were accepted the country's dialysis facilities would be saturated within two years. The survey showed that the situation in some parts of Britain was much worse than in others. The 14 million people living in the Birmingham, Manchester, and Sheffield regions were served by nine dialysis units, which were treating 144 patients; at the same time a similar population living in the London Mietropolitan regions was served by 12 units treating a total of 393 patients. Clearly the need for an expansion of services in the North Midlands is particularly pressing. Moreover, in Europe as a whole the situation is even worse. Last year 217 units treating a total of 2,816 patients completed the questionnaire sent out by the European Dialysis and Transplant Association. ${ }^{8}$ At least another 83 units failed to complete the forms, but it appears that 300 units are serving a population of over 500 million people. On this basis it seems that we have rather more units than our Continental colleagues and that each unit is relatively more active.
Renal transplantation from cadaveric donors is not yet sufficiently advanced to provide a solution. The Department of Health is supporting 12 transplant units in England and Wales. Most are designed to treat a maximum of 50 patients annually, though none has yet achieved this rate, and theoretically 600 patients could be treated this way each year. Nevertheless, despite outstanding results from individual units, ${ }^{910}$ the last report of the Transplant Registry ${ }^{11}$ shows that on average only $41 \%$ of transplants from cadaver donors continue to function beyond two years. A large proportion of the patients with failed grafts will return to regular dialysis treatment.

Clearly we have not yet solved the problem of the patient with terminal renal failure. With existing techniques any solution will be very expensive in terms of staff and equipment ${ }^{12}$ and policy decisions must be made on the priority of renal failure programmes and of any other organ support systems that may be developed in the future. This is particularly important in a country which claims to provide a comprehensive National Health Service. Until there is a major change in the facilities that are available most patients who require treatment will not be offered it and invidious selection policies will continue to operate. As Dr. Branch and his colleagues have pointed out, many suitable patients are aged over $\mathbf{5 0}$ and it seems certain, for the time being at least, that it will be necessary to impose arbitrarily low upper age limits for treatment.

\footnotetext{
1 de Wardener, H. E., in Ciba Foundation Symposium: Ethics in Medical Progress with Special Reference to Transplantation, p. 104, ed. G. E. W. Progress with Special R. O'Connor. London, Churchill, 1966.

2 Thaysen, J. H., Proceedings of the European Dialysis and Transplant Association, 1966, 3, 138

3 Sheil, A. G. R., et al., Lancet, 1969, 2, 917.

- Branch, R. A., Clark, G. W., Cochrane, A. L., Jones, J. H., and Scarborough, H., British Medical fournal, 1971, 1, 249.

Meadow, R., Cameron, J. S., and Ogg, C. S., Lancet, 1970, 1, 707.

6 Department of Health and Social Security, Annual Return on Intermittent Haemodialysis fuly 1969-fune 1970. London, 1970.

7 Lancet, 1970, 2, 968.

Drukker, W., Haagsma-Schouten, W. A. G., Alberts, C., and Baarda, B., Proceedings of the European Dialysis and Transplant Association, 1970,7, 3. 9 Hume, D. M., Leo, J., Rolley, R. T., and Williams, G. M., Transplantation Proceedings, 1969, 1, 171.

10 Calne, R. Y., Shackman, R., Nolan, B., Petrie, J., and Woodruff, M., Lancet, 1, 671.

1 Murray, J. E., Barnes, B. A., and Atkinson, J., Eighth Report of the Human Kidney Registry, Transplantation, in press.

12 Ogg, C. S., Biomedical Engineering, 1970, 4, 190.
} 